\title{
Formação e Gestão de Recursos Humanos: Novas Fronteiras
}

KENNETH ROCHEL DE CAMARGO JR.

A história das políticas públicas na área de saúde no Brasil registra avanços, sobretudo no período historicamente recente que se inicia com a chamada "transição democrática". O reconhecimento da idéia de saúde como direito, registrado em nossa constituição, a implantação - em que pesem todas as dificuldades - progressiva do SUS e o estabelecimento de políticas setoriais inovadoras, como por exemplo nas áreas de HIV/AIDS e de saúde mental, são conquistas inegáveis e importantes.

Em parte por conta desses mesmos avanços, avolumam-se evidências de que alguns obstáculos já amplamente identificados persistem, e do seu correto enfrentamento dependem a continuidade e expansão bem-sucedida destas mesmas políticas. Em particular, ambiciosas tentativas de "reorientação do modelo assistencial", como o Programa de Saúde da Família, tema recorrente de artigos nesta revista, são fundamentalmente dependentes da adequada qualificação dos profissionais envolvidos no processo.

Tendo em vista este aspecto estratégico, os artigos temáticos deste número de Physis abordam a formação e gestão de recursos humanos em óticas variadas e inovadoras, cada uma a seu modo.

Abrindo este número, Bulcão e Sayd apresentam, num texto originado da dissertação de mestrado da primeira (orientada pela segunda), estudo sobre os valores ligados à profissão de um grupo de médicos-professores de uma Faculdade de Medicina do Rio de Janeiro, aspecto fundamental do processo de reprodução do ethos profissional.

No texto seguinte, Soares et al. trazem uma reflexão sobre inovações no ensino de conteúdos de Saúde Coletiva na graduação em Medicina, com base numa experiência de utilização da interação via internet como ferramenta auxiliar do ensino.

Finalmente, no último artigo do bloco temático desta edição, Pierantoni e 
Kenneth Rochel de Camargo Jr.

Vianna analisam uma experiência de implantação de um sistema informatizado de gestão de recursos humanos como parte de uma estratégia de avaliação da implementação de políticas públicas.

No artigo de atualização, Birman discute a questão da fraternidade, em vista das novas condições de mal-estar na atualidade, buscando rever o descompasso existente entre os instrumentos psicanalíticos de escuta e as modalidades contemporâneas de sofrimento.

Nos artigos de demanda livre, Facchinetti relata uma perspectiva histórica do desenvolvimento da psicanálise em nosso país, correlacionando-o ao marco cultural mais geral do modernismo. Na seqüência, Trad analisa os impactos do processo migratório, com base na experiência de emigrados brasileiros em Barcelona. O artigo seguinte, de Andreazzi e Kornis, extraído da tese da primeira (orientada pelo segundo), aborda as relações entre o setor público e o privado na área de Saúde na década de 90 (pós-implantação do SUS, portanto), apontando para os limites e possibilidades do modelo, com atenção para alguns pontos como as perspectivas de regulação do setor privado. Por fim, Chazan discorre sobre os desdobramentos das inovações tecnológicas nos métodos de produção de imagens em medicina na própria concepção contemporânea de corpo e de Pessoa. 